\title{
Understanding Complex Human Ecosystems: The Case of Ecotourism on Bonaire
}

\author{
Thomas Abel
}

ABSTRACT. It is suggested that ecotourism development on the island of Bonaire can be productively understood as a perturbation of a complex human ecosystem. Inputs associated with ecotourism have fueled transformations of the island ecology and sociocultural system. The results of this study indicate that Bonaire's social and economic hierarchy is approaching a new, stable systems state following a 50-yr transition begun by government and industry that stabilized with the appearance of ecotourism development and population growth. Ecotourism can be understood to have "filled in" the middle of the production hierarchy of Bonaire. Interpreted from this perspective, population growth has completed the transformation by expanding into production niches at smaller scales in the production hierarchy. Both a consequence and a cause, ecotourism has transformed the island's social structure and demography. The theory and methods applied in this case study of interdisciplinary research in the field of human ecosystems are also presented.

\section{INTRODUCTION}

In this paper, I explore the impacts of ecotourism development on the socioeconomic structure of a small island in the Caribbean. Understanding the effects of an unplanned intervention or perturbation of whole systems is an appropriate subject of study for the interdisciplinary science of complex systems as advocated by Holling (1998). This paper presents the results of an interdisciplinary social and ecological study (Abel 2000) of whole-systems transformations brought about by an exceedingly popular formula for economic development, namely, ecotourism. Although ecotourism development on the island of Bonaire, as elsewhere, aims to minimize negative impacts on local populations and environments, I expected that the many new inputs to the region beyond the narrow tourism sector would bring changes to the economy and ecology of the island. Those transformations can be understood and evaluated from the perspective of complex systems.

To understand the impacts of tourism, the study used a form of ecological economics known as "emergy accounting." A full explanation of emergy accounting can be found in Odum (1996). In brief, emergy accounting evaluates the energy contributions to a service or product, of natural or human design, rather than the amount it sells for in the marketplace. It is thus a donor value, which contrasts with the type of receiver value used in conventional economics. Emergy is the "energy memory" (emergy) of all prior work contributed by ecosystems, global processes, and human systems. Unlike traditional energy currencies of calories or joules, emergy values account for the chain or web of processes at different temporal and spatial scales that contributed to the production of the service or product. Emergy therefore belongs within the emerging field of complex-systems science that studies multiscaled self-organizing systems. As a single currency, emergy can be used to compare dissimilar natural resources and ecosystem objects, as well as social and cultural capital.

The case study that concludes this paper focuses on transformations of the socioeconomic structure of Bonaire. The principles of hierarchy and selforganization used in studies of complex systems are applied to recent and historical data from Bonaire to produce some aggregate measurements of change. The results indicate that the preconditions for the development of ecotourism on Bonaire were created by government spending, the presence of nearby refineries, and the arrival of some small export industries, a setting from which ecotourism "took off" in the mid 1980s. It is argued here that ecotourism represented a "filling in" of the middle scales in a production hierarchy. By doing this, ecotourism amplified production both at smaller and larger scales, reaching a new and relatively stable regime in a 50-yr 
self-organized transition. It is further argued that system self-organization in this development context has led to an expanded labor population. Although not uncommon in a development context, it is suggested here that population growth is a "product" of wholesystem self-organization in the context of material and energetic influxes, the effects of which are increased fertility and immigration. The end result is a model of population pull, rather than the model of population pressure that is more common in the anthropological literature.

Before these results are presented, I will review and discuss a model of sociocultural systems. The rest of the paper will apply this sociocultural systems perspective to understanding the impacts of economic development on the social structure of the island of Bonaire.

\section{SOCIOCULTURAL SYSTEMS}

This paper makes liberal use of systems diagrams, a well-known graphic technique for representing systems of any kind and one that is most prominently associated with H. T. Odum (Odum 1971, Odum and Odum 1976, Odum 1983, Odum 1996, Odum and Odum 2001). Although this technique does have shortcomings for anthropologists (see Ellen 1982), systems diagrams can be of great value as both a heuristic and an analytical tool. Systems diagrams force the researcher to make explicit the components of an argument, exposing any proposition to its material situation. Systems diagrams, by design, demand that a modeler identify the energetic, material, or information "sources" (circles) that enter and animate an analytic frame. "Storage" symbols (tanks) within a frame further account for the concentrations of matter, energy, and information that drive opportunistic pathways. Systems diagrams are simple to construct from a handful of symbols and can be easily used by interdisciplinary teams to brainstorm on complex questions. Analyses based on systems diagrams can produce indices for comparison across systems. Simultaneously, systems diagrams can lead directly to the production of computer simulations (Odum and Odum 2000).

Systems diagrams were used extensively in this research project. In Fig. 1, a systems diagram of a "sociocultural system" is defined to include material assets, people, social structure diversity, cultural models, and language. This diagram also includes the often ignored interactions between these components, the natural environment, and the people who continuously produce and renegotiate their forms. These components always co-occur.

The biosphere context of the sociocultural system is represented in highly aggregated form to the left in the diagram. Natural resources in earth systems are commonly grouped into the categories of renewable, e.g., sun, tide, and uplift; slow-renewable, e.g., timber, topsoil, groundwater; and nonrenewable, e.g., coal, oil, natural gas, metals. This categorization scheme indicates the turnover time of these resources relative to human life-spans. For example, because a cleared forest may not fully regenerate in the lifetime of a logger, forest timber is considered a slow-renewable resource. Coal or oil, although renewable on the time scale of geologic processes, are nonrenewable at the scale of people or even civilizations.

The interactions among the components of the sociocultural system and among ecosystem resources are aggregated into one interaction symbol. This indicates that the dynamics of each affects the others. The fact that the nonrenewable storage in the diagram is not reproduced, i.e., there is no inflow, only outflow, at this temporal scale, indicates that there are limits to the growth of our contemporary sociocultural systems, which are systems that supplement renewable energies with fossil fuels.

In Fig. 1, the source of cultural change is not restricted to single biological "prime movers" such as population pressure, which is popular in many cultural evolution models (Harris 1977, Johnson and Earle 1987). Change in open self-organizing systems is expected and incessant because of the teleomatics of energy dissipation, which Prigogine and Stengers (1984) describe as an "arrow in time." A sociocultural system is conceived as a self-organizing system of amplification, constraint, and pulsing dynamics with many shifting limiting factors within ecosystems and within itself; population density is only one of these factors. Within these material constraints are situated the human symbolic systems of cultural models, which possess a structure and dynamics of their own. Intentionality and agency can be understood to selforganize within a highly dynamic human and extrahuman environment.

The label "sociocultural system" was chosen over "culture" in Fig. 1 because the latter is often taken to mean human symbolic behavior alone. The term "sociocultural system" more precisely conveys the fact 
that humans have co-evolved an integrated repertoire of symbolic behavior plus material assets, technologies, and social organization, each within language contexts. In Fig. 1, these components are identified with separate "storage" symbols. They are assembled from left to right, representing increases in replacement time. They are joined by a single interaction symbol, indicating that no component is "prior," each is potentially limiting, and all may amplify production with autocatalytic feedback, as represented by arrows from storages returning to the interaction symbol. In systems terms, they are coproducts of humanity.

Fig. 1. Sociocultural system. In this systems diagram, a sociocultural system includes "storages" of material assets, diverse social structures, people, cultural models, and language. These components always co-occur. Although they are not shown in every drawing, they are assumed to exist wherever people appear. Systems diagrams are always drawn from one perspective in a simplified and focused manner. There are alternative systems diagrams to this drawing of a sociocultural system (Odum 1971, Odum and Odum 1976, Odum 1983, Odum 1996); see Abel (2002) for a discussion of these differences.

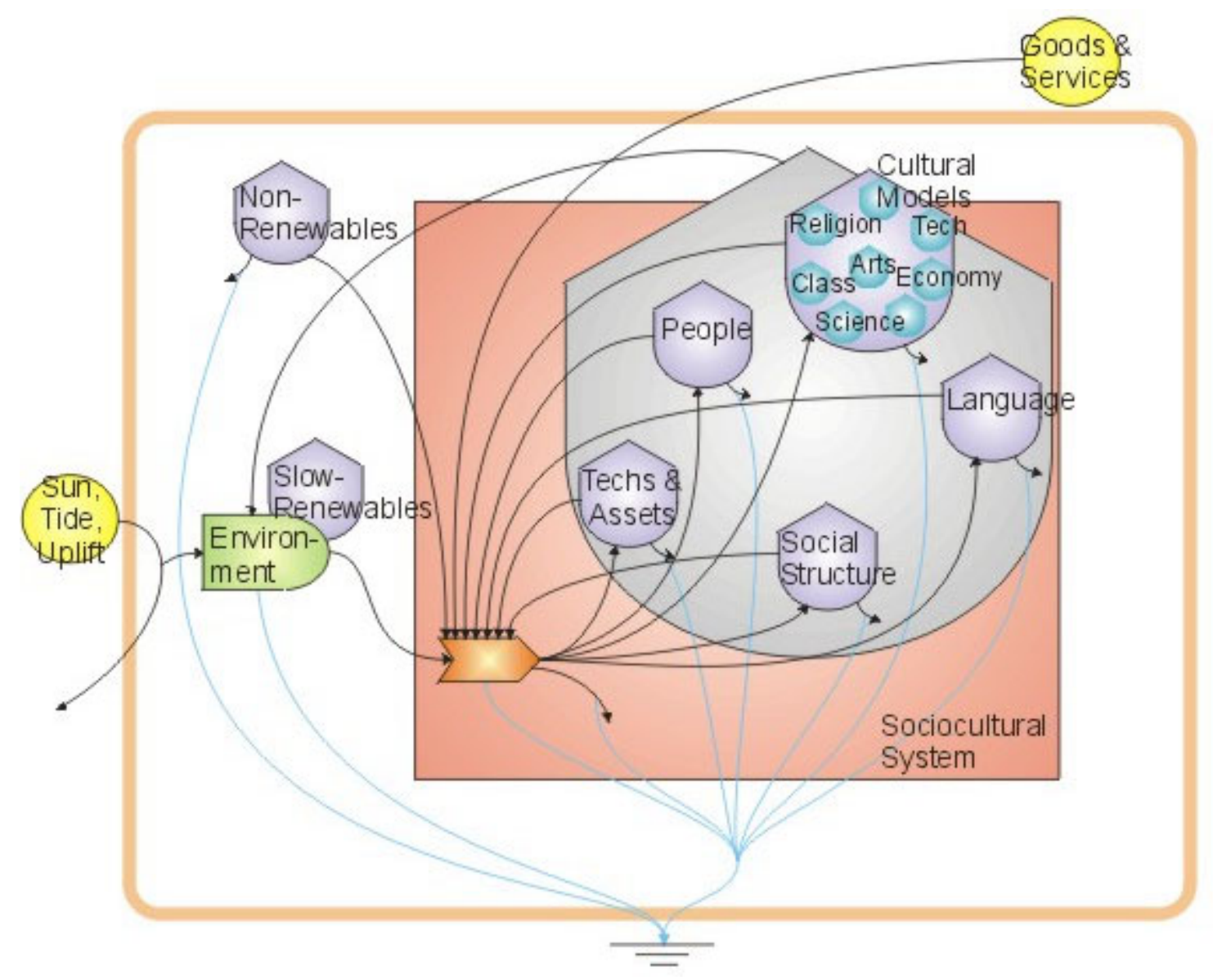

The storage of symbolic "culture" is here labeled "cultural models" to avoid confusion with the former imprecise term, to accentuate the fact that symbolizing behavior is only one component within the larger sociocultural system, and to draw our attention to the contention that symbolic culture is composed of countless cultural models. These models interact by sharing themes or postulates (Holland and Quinn 1987), are constantly evolving or being renegotiated
(Giddens 1984, Bourdieu 1989), and constitute a hierarchical system that profoundly and fundamentally shapes the ways in which we see the world.

In this model of a sociocultural system, cause is always "multicause," with impetus from multiple spatial and temporal scales within and beyond the sociocultural system. Furthermore, causality may continuously shift in time as determinant storages and 
flows are themselves transformed by self-organization of the system whole. As a nonequilibrium thermodynamic human-ecosystem, we are wise to pay particular attention to the objects on the left of Fig. 1, i.e., renewable, slow-renewable, and nonrenewable resources, because they provide the energy that supports the sociocultural system that emerges on the right.

Fig. 2. An energy transformation hierarchy adapted from Odum (1996:23). (A) Spatial view of units and territories, (B) energy network including transformation and feedback, (C) aggregation of energy networks into an energy chain, (D) bar graph of energy flows for the levels in an energy hierarchy, and (E) bar graph of emergy (energy memory) flows for the levels in the same hierarchy. The emergy flow is the same for each pathway, but the energy flow decreases at each step.

A.

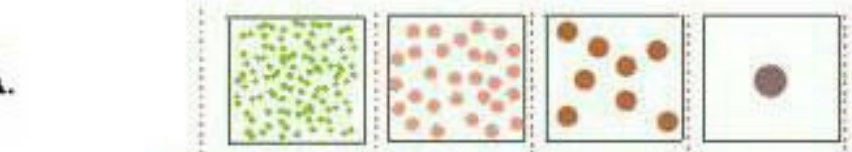

B.

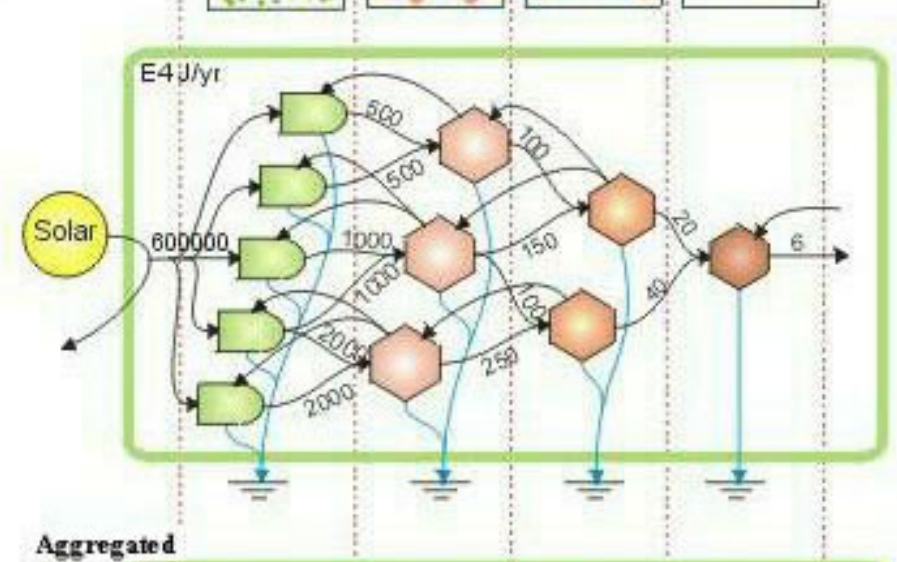

C.

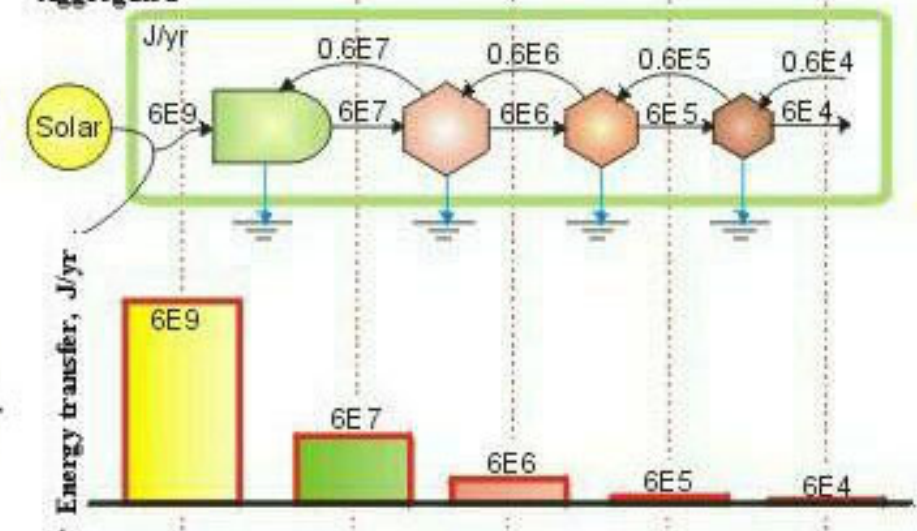

E.

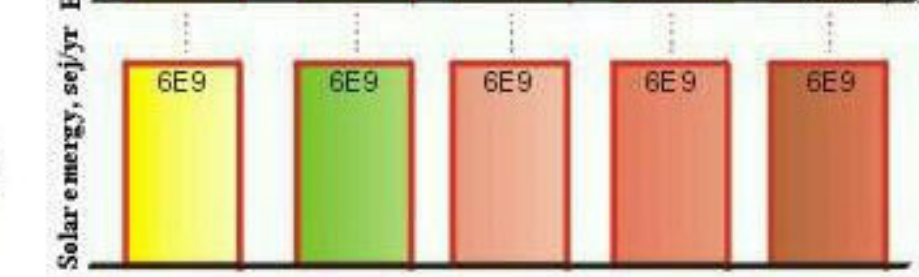

\section{A human-ecosystems model of social structure}

It is a principle of systems science (Odum 1996) that open systems such as ecosystems are nonequilibrium thermodynamic systems that self-organize into energy transformation hierarchies. Fig. 2 depicts such a hierarchy from five different perspectives. Fig. 2B shows a typical hierarchy that could be an ecosystem with plant producers on the left and animal consumers on the right, concentrating food in a food web that is 
capped by one or several top carnivores. The energy that moves through that web is highlighted in the Fig. 2D bar graph, with energy amounts shrinking as they move through the web. Fig. $2 \mathrm{E}$ shows how flows of emergy, i.e., the ecological-economic currency mentioned above, remain constant throughout a selforganized network.

Fig. 3. Social structure as an ecosystem web. This figure follows the web format of Fig. 2B. Here the "structure" storage of Fig. 1 is eliminated, and in its place is a direct depiction of the energy-transforming political-economic structural hierarchy.

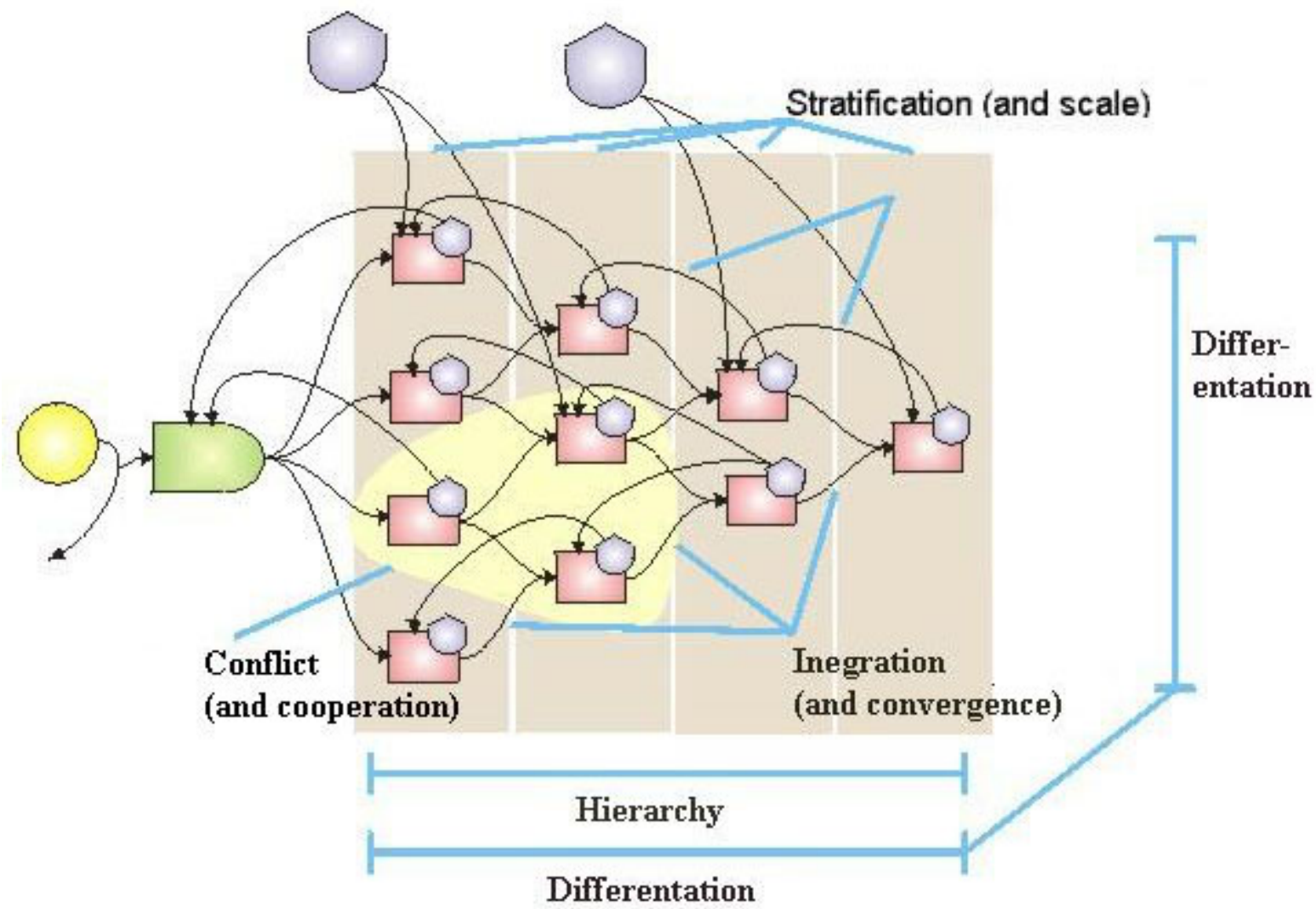

This model of system structure and function can be applied to the social structures within sociocultural systems. Fig. 3 is one systems approach to human social structure, which redraws Fig. 1 with one major difference. Other configurations have been proposed (Odum 1971, Odum and Odum 1976, Odum 1983, Odum 1996); see Abel (2002) for a discussion of these differences. In Fig. 3, the storage of structure is eliminated, and in its place is an actual network or hierarchy of household types in a political-economic structure. Each of the households contains the other four storages, assets, people, cultural models, and language. In state societies, households differentiate themselves by the alliances they form, the assets they control, and the technologies they command, all within an ecological and demographic context.
For the purposes of this paper, social structure will refer to households that are differentiated by income, resource control, coercion control, and economic function. This conceptualization of structure, defined by the division of labor and a political-economic hierarchy or inequality, has a long tradition in social science and appears in many related forms (Spencer 1876, Durkheim 1893, Hawley 1950, White 1959, Weber 1964, Marx 1967, Adams 1988).

Some households in a production hierarchy may control corporations. Most, however, are producers of people, who represent labor in a market economy. Thanks to their cultural models and memories, people reproduce sociocultural systems in a very energyefficient manner. For this reason, Wicken (1987) characterizes sociocultural systems as "informed" 
auto-catalytic systems. From an ecosystems perspective, however, humans are the top consumers, i.e., the products of hierarchies of production, and are not themselves energy sources as is suggested by terms like "social capital" or "cultural capital" (Bourdieu 1986). The control of productive assets by households places them within production hierarchies that exhibit characteristics similar to those of the hierarchies of other complex systems, e.g., autocatalytic growth and pulsing, energy dissipation, emergent properties at multiple scales, and others.

Figure 3 depicts many important social concerns that are absent from other network models: power, hierarchy, differentiation, integration, stratification, and conflict (Turner 1998:529). Power is represented in the diagram as feedback from storages. Power feedback comes from storages of judicial or police assets, from large storages of goods owned by wholesalers who exert control over retailers, or from other asset storages. We are all familiar with the storages of assets controlled by our employers, who use them to exert power over our own actions. In the figure, stratification and scale are represented by the different steps in the hierarchy of political-economic energy transformation. Integration and convergence are represented by the cooperation shown by the actors who bring about the convergence of goods and services for the production of new products or services at larger scales. Hierarchy is represented by the total web from left to right. Differentiation is represented by the division of labor in the total web, from left to right and top to bottom. Conflict can be a product of competition for resources from a smaller scale or from the exertion of power. It should be expected that within a social structure, as in a food web, conflict or direct competition is minimized via behavioral or morphological changes.

Finally, Fig. 4 is an aggregated model of Fig. 3 (compare also to the aggregated diagram in Fig. 2C). This figure provides a detailed look at the concept of sociocultural hierarchy produced by the ownership or control of asset storages. As depicted in this diagram, labor households control very modest storages of assets. Owner/manager households, by contrast, control large asset storages that can be used to feed back and amplify production to themselves. This simple strategy, it is argued (Abel 2000:366-456), has co-evolved with human populations through millennia, resulting in the emergence of sociocultural hierarchy in chiefdoms, archaic states, modern states, and world systems. Fig. 4 depicts owner/manager households that control vast storages of assets ranging from machines and factories to the legal deeds and police/military apparatus that guarantee their private ownership.

Fig. 4. Socioeconomic structure of households and storages. Dotted lines are money flows, which move countercurrently to emergy, i.e., energy, materials, and information, flows.

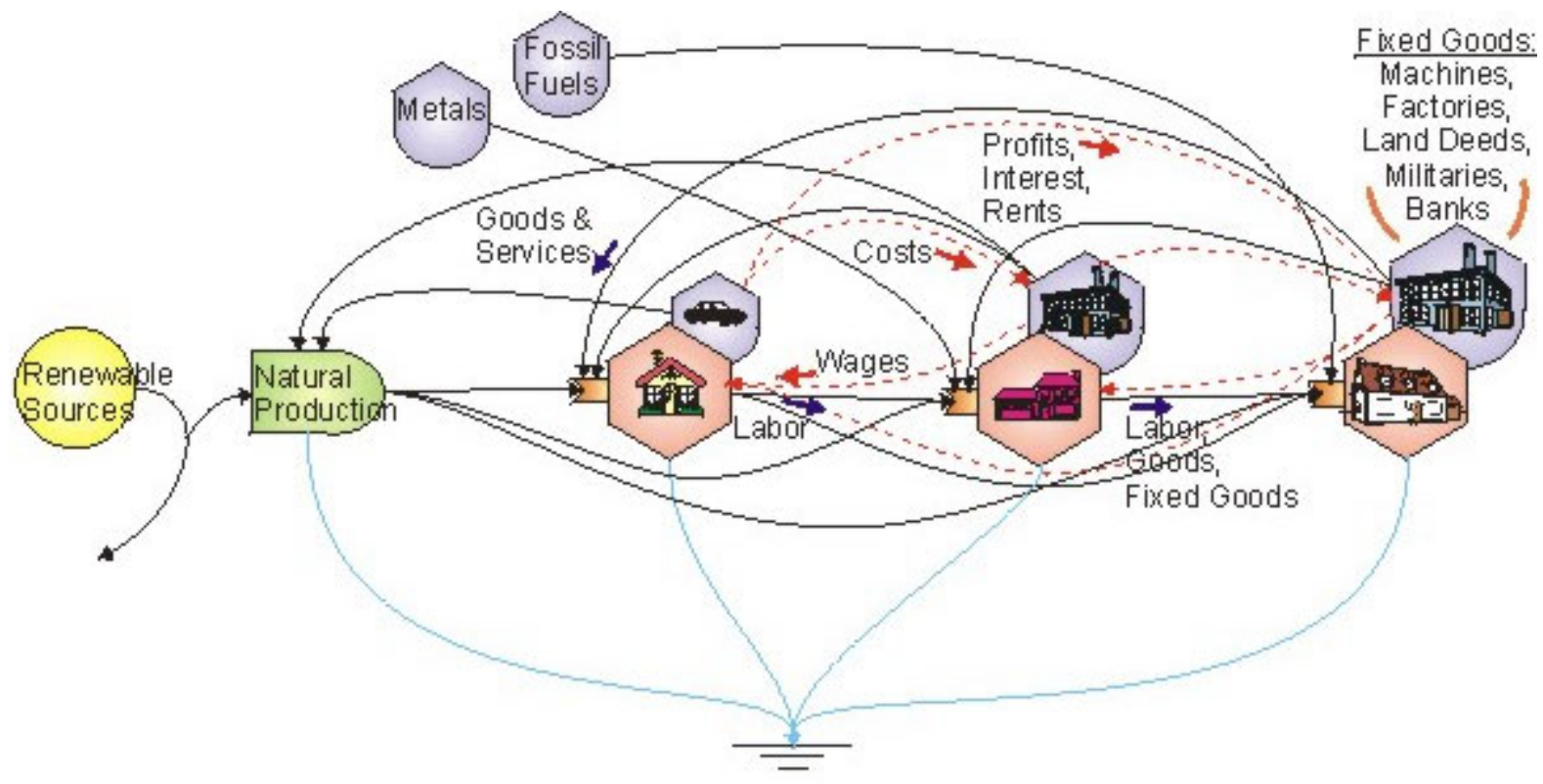


It should be emphasized that there is an important "informational" component included among the asset storages of any household. By definition, "division of labor" implies that individual laborers in state economies are specialized in their knowledge and skills. Those cultural models, which compose that specialized training, are the informational component that helps to construct and maintain the web of social structure.

Fig. 5. Netherlands Antilles and Aruba.

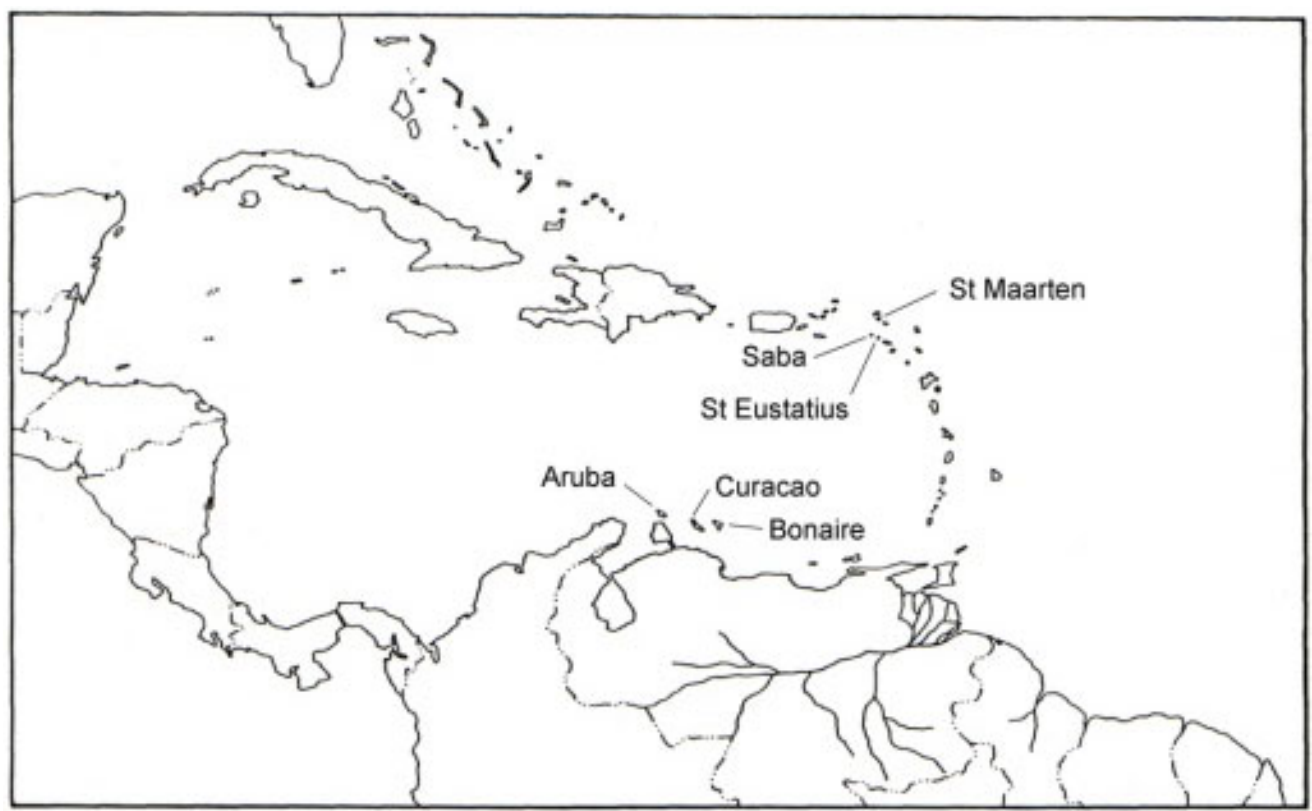

\section{EMERGY ANALYSES OF BONAIRE'S SOCIOECONOMIC STRUCTURE}

The case study for this paper was an interdisciplinary study conducted on the island of Bonaire in the Netherlands Antilles (Abel 2000). In the late 1980s and 1990s, ecotourism based on scuba diving grew rapidly on Bonaire (Fig. 5). At the time the fieldwork was carried out, I expected to be able to observe and explain the multiple-scaled, hierarchical impacts of this development event. There were four spatial scales of analysis in the research: multinational, island, inter-island economic, and household-farm. This paper will address changes to inter-island economic production and the accompanying structural self-organization.

The Earth's biosphere is an open thermodynamic system that is maintained ultimately by the sun, earth deep heat, and lunar gravity (Brown and Ulgiati 1999, Odum 2000). Over evolutionary time, it can be said that sociocultural systems self-organized with environmental systems in the biosphere, each contextualizing the other. These renewable sources are emergy sources that support human-ecosystems and sociocultural systems on Bonaire and elsewhere (Fig. 6).

Figure 6 is a highly aggregated context diagram of Bonaire's sociocultural system. Although its focus is the human system, it is essential to identify the driving energies from various spatial-temporal scales that make the system possible. The Bonaire sociocultural system is dependent upon environmental production, geologic processes, ocean currents, imported fossil fuels, other goods and services, financial aid, loans, and other sources. These are identified in the context diagram and were evaluated in the island-scale analysis (Abel 2000).

It should not be forgotten that Bonaire, like other states or nations, should be situated at still larger scales (Fig. 7) as a component within one of several economic world systems (Wallerstein 1974, Sanderson 1995, Hall 2000). Discussion of this context of asymmetrical trade relations can be found in Abel $(2000,2002)$. Multinational world systems should be studied holistically as complex systems using the same household-focused politicalecological methodology applied here. 
Fig. 6. Bonaire sociocultural system and its resource support. Sun, earth deep heat, and lunar gravity are energy sources of the biosphere. Sunlight produces wind, waves, and rain, important renewable sources shown on the left. Lunar gravity produces the tides. Earth deep heat is the source of geologic processes. These sources are joined in this diagram by other imported sources, many based on nonrenewables, shown on the right.

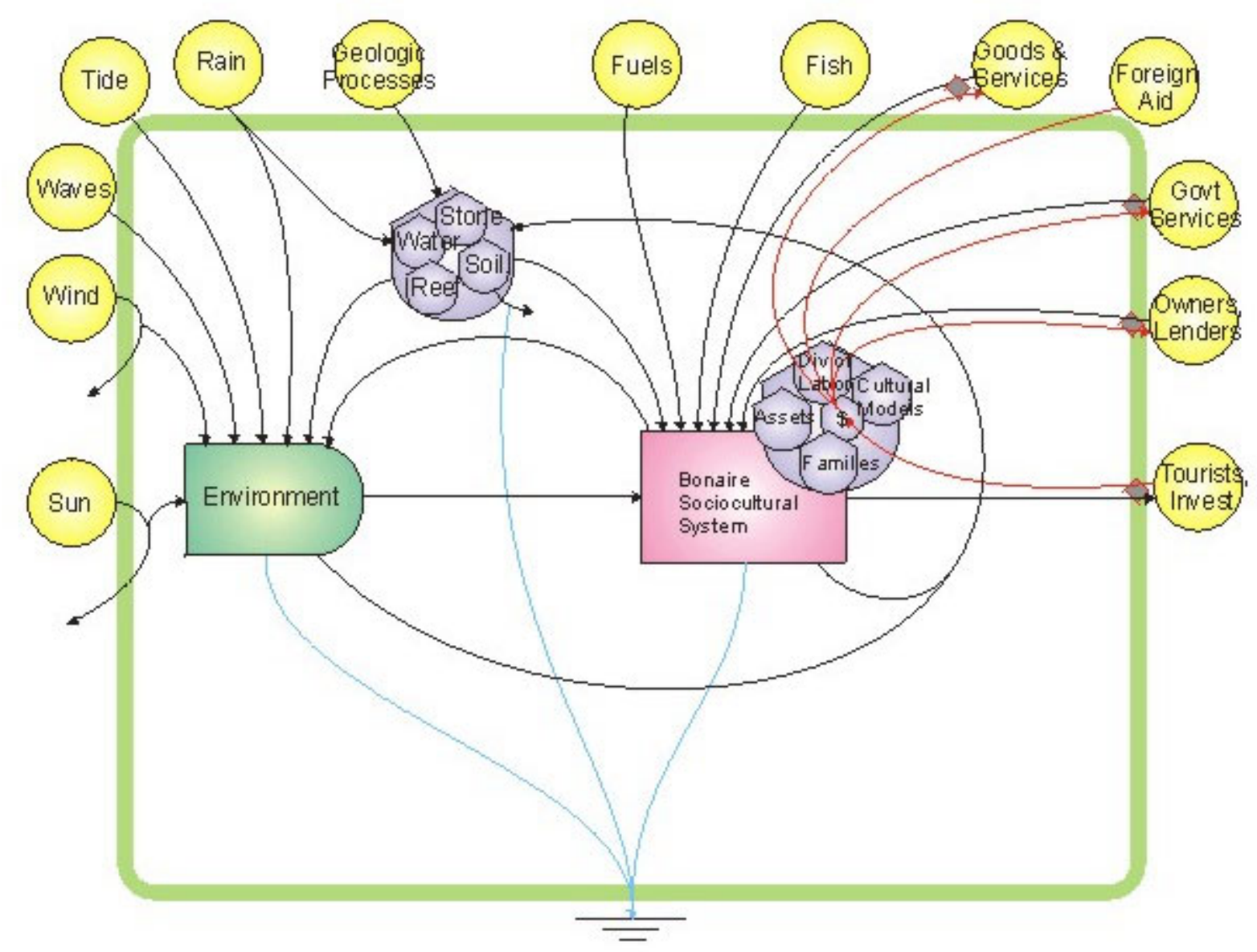

\section{Social structure and energy transformation on Bonaire}

On Bonaire, human subsistence production is manifest in the web of market and nonmarket production subsystems that form an energy transformation hierarchy similar to the one seen in Fig. 2. Because it is a small island, many common economic production subsystems are not found on Bonaire. Fig. 8 provides a way to depict the production subsystems that do exist on Bonaire and the ways in which they are related to one another. The features of this drawing (compare to Fig. 2B) depict the unique nature of the Bonaire web of socioeconomic production subsystems.

Figure 8 is an unusual systems diagram. Systems diagramming is normally used to simplify a complex network of interactions so that determinant flows and processes can be identified. Figure 8 is intended instead to be thematic, i.e., to depict a pattern of flow and process.

As a model of a sociocultural system, Fig. 8 has a number of other unique features. As discussed above, the individual units are household types. Each household contains the storages of a sociocultural system, assets that include the house itself, people, a small division of labor, cultural models that derive from education and experience, and language, which is negotiated and reproduced by each household in interaction with others. In a recursive sense, households are embedded within a larger sociocultural system. 
Fig. 7. Bonaire within its world system context. A hierarchy of nations organized by trade forms an economic world system. Trade relations are asymmetrical in emergy terms, with core nations receiving more than they are giving (Odum 1996, Abel 2000). Each nation has its own ecosystems and storages of renewable and nonrenewable resources, which are the ultimate sources of the emergy (energy memory) in trade goods.

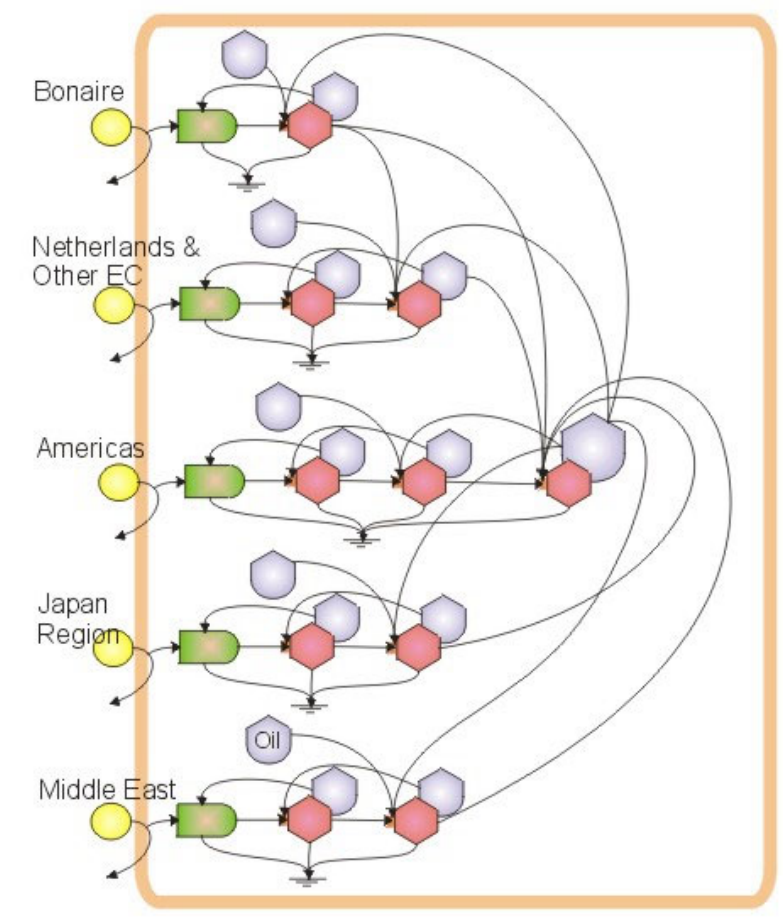

The units in this diagram represent household types and not individual households, of which there are approximately 3300 on Bonaire. Although it is difficult to classify them, this is routinely done for biological species and can be done here with resource data. Owner/manager households, which include the capital assets of their companies (discussed below for Fig. 9), clearly have distinctive emergy input signatures, emergy storages, and production output flows, i.e., the product or service outputs, within a corporation type. For instance, hotels, regardless of their size, will have certain large and determinant flows and storages of electricity, water, gas, construction materials, labor, buildings, and landscape, in addition to their more commonly recognized production output flow, a tourism product. Labor households may also be similarly grouped.

Another unusual feature of this drawing reflects Bonaire's import-dependent economy. Few natural assets exist on Bonaire that can support the intensive development infrastructure that is required by the global market for high-end diving ecotourism. Fossil fuels, construction materials, food, and manufactured goods must be imported. This fact is accentuated by the large flow of imported food and goods, which are subsequently pushed "downhill" to retailers and then reconverged to the right.

Data for households and companies were collected from interviews and published sources during 14 months of fieldwork. Two household surveys were carried out. Informal interviews were conducted with part-time farmers, and a model was constructed of farming on Bonaire. Formal interviews with owners and managers of companies were also conducted. More than 30 emergy analyses were performed. From those analyses, the households with companies are arranged in Fig. 8. Households with lower emergy flows and storages are placed further to the left, and those with large flows and storages are placed to the right. This is analogous to the ecosystem webs seen in Fig. 2B, in which species that converge greater amounts of emergy and have slower turnover times are placed on the right, whereas species with more individuals but less emergy converged and stored per individual are placed on the left.

Figure 9 is an aggregated diagram of Fig. 8. This more conventional diagram groups processes by energy flow into trophic groups. This highly simplified diagram makes visible the natural plant and animal production that in part supports the Bonaire system. Notice that the Bonaire sociocultural system has been broken into three lumps. A second scale of business subsystems was proposed. These businesses exist on the island as single companies. It is argued that these businesses belong at a regional scale due to their functional roles. Given the area and population density of Bonaire, it is reasonable that there is only one airport, one electric plant, one water desalination plant, one port, one local inter-island shipper, one salt works, etc. These business subsystems are regional in scale because they link Bonaire to the larger world.

Fieldwork data collection on Bonaire focused on flows of goods and services into households and businesses. Based on the types and numbers of businesses, it was possible to estimate emergy inflows into labor households and businesses, hereafter called "business subsystems." Total subsystem emergy inflows by type are compared in Fig. 10. Perhaps surprisingly, labor households were found to have nearly the largest 
emergy flows. Labor households use water, electricity, and purchased goods and services. They control natural emergies in farms and assets such as houses, automobiles, etc. The high total, however, is due to the fact that there are more than 3000 total labor households on Bonaire.

Fig. 8. Bonaire's web of socioeconomic production.

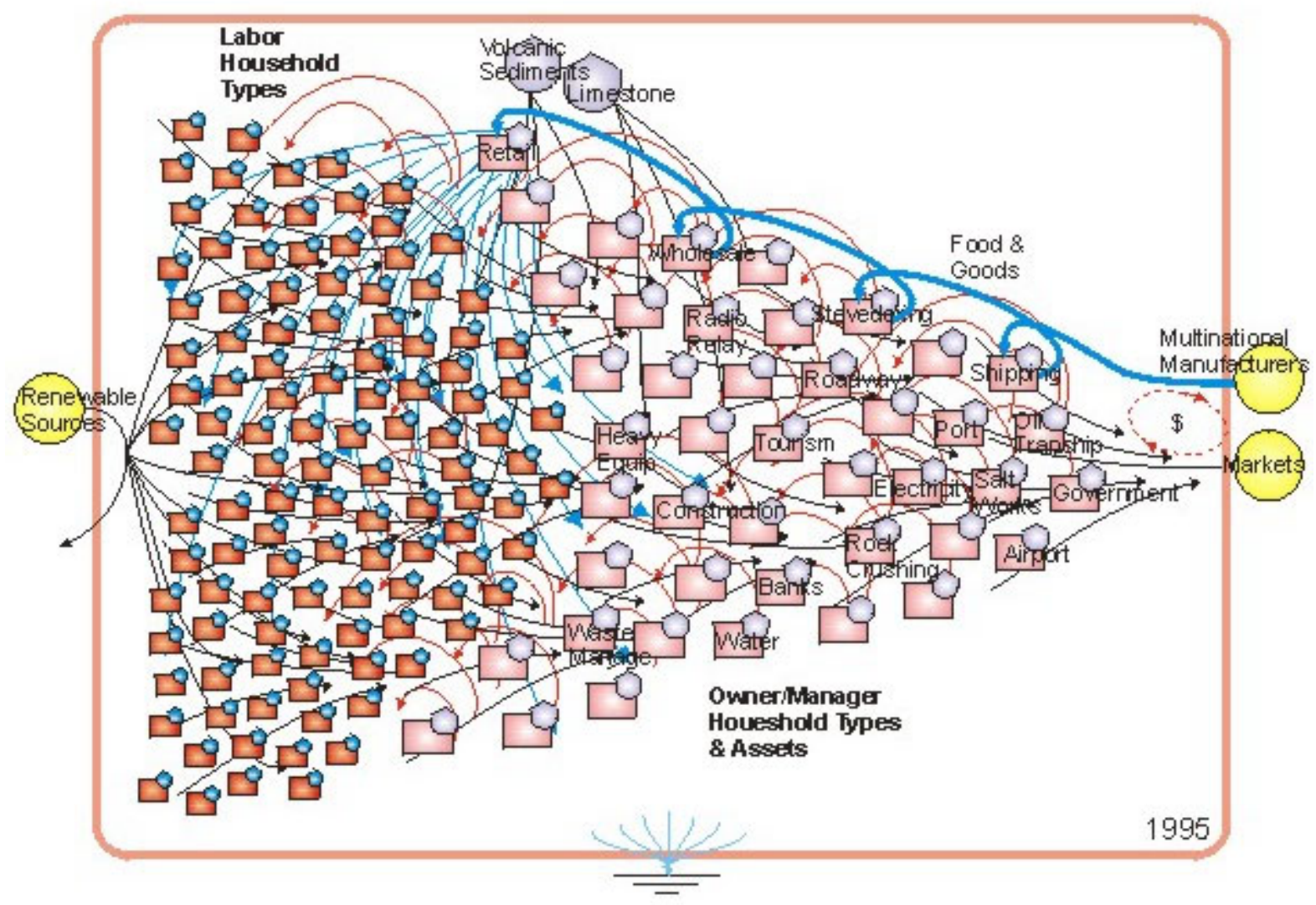

\section{RESULTS}

As previously explained, a web of production subsystems can be constructed for Bonaire that is analogous to an ecosystem web (Fig. 2B). In an ecosystem hierarchy, more energy is used and degraded at the base of the food web, but less emergy is captured per individual organism because there are numerous small individuals at the base and fewer larger individuals further to the right in the web (Fig. 2A).

In Fig. 10, tourism and the construction subsystem capture the largest emergy flows along with labor households. The next three subsystems with high emergy needs are single companies, the airport, the oil trans-shipment terminal, and the electricity plant.
Dividing the emergy totals in Fig. 10 by the numbers of individual units produced the graph of emergy per unit in Fig. 11. In the higher trophic groups, there is less energy, and the available emergy is concentrated in fewer organisms. Humans are at the apex of most natural food webs the world over. On top of that web I have modeled an additional web of households and production subsystems. This web was depicted in the web drawing in Fig. 8. The hierarchy in Fig. 11 determined the arrangement of subsystems in the web in Fig. 8. The subsystems on the left in Figs. 8 and 11 exist in great numbers and capture less emergy per establishment. The subsystems on the right are few and capture much emergy per subsystem. This is analogous to an ecosystem web. 
Fig. 9. Aggregated socioeconomic system.

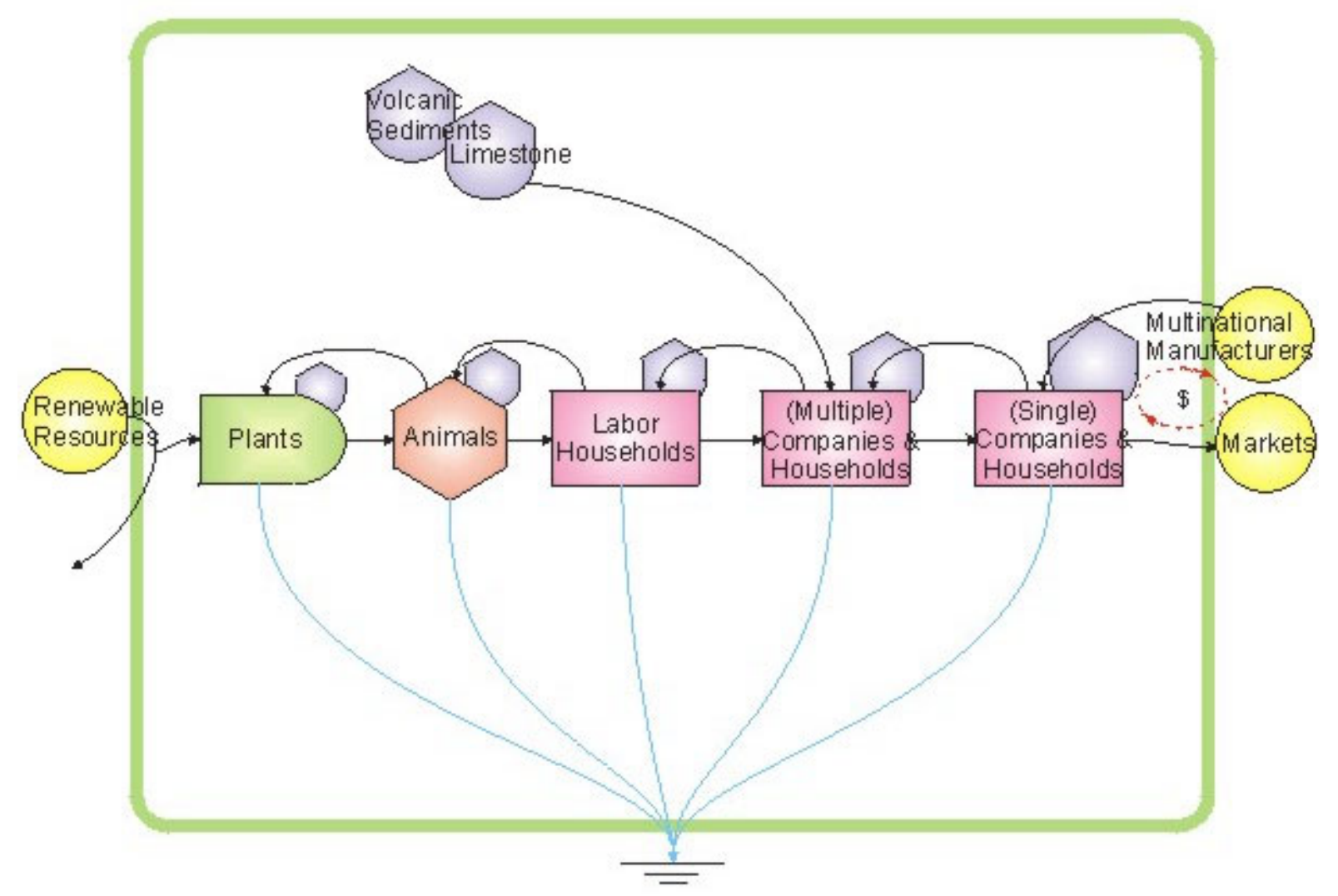

Figure 12 is a historical count of business subsystems on Bonaire. These numbers come from the Chamber of Commerce and Labor Office on Bonaire, and they are admittedly imperfect because of prior registration policies (Labor Office 1993). Values for the years past might have been higher, and there are surely some industries that were omitted. The intention of this graph, however, was to identify the trend of subsystem complexification. From this graph, it can be seen that businesses have increased in both number and type. Fig. 13 depicts this transformation with sequential systems diagrams.

The human energy hierarchy expressed as households in Fig. 9 is presented in detail in Fig. 14, which depicts total emergy values for the four years in Fig. 13. In Fig. 14, the columns represent emergy values and should be compared to Fig. 2E. As was discussed for Fig. 2E, the emergies at each scale of a hierarchy are expected to be equivalent. This occurs as systems self-organize for energy dissipation, a phenomenon referred to as "maximum empower" by Odum (1996). In Fig. 14, the three emergy scales are nearly equal magnitudes in the 1950 graph and again in the 1995 graph. This series depicts the self-organization of Bonaire's economy in the last half-century. Note that this transformation in 1970 was led mainly by the energies entering the island in the export industries and into infrastructure. Prior to the tourism boom that began in 1985, the economy had already dramatically expanded the island's population and its middle sector of supporting industries. This expansion was again led by the doubling of imported emergies into export industries and the infrastructure.

The lower right graph in Fig. 14 shows increased emergies at all three levels in 1995, but especially at the "Many" and "Multiple" levels. This is due to the exploding population and the burgeoning of industries to support tourism development. Although not shown on this graph, additional emergy inputs are now also entering the ecosystem levels of the hierarchy to the left of these bar graphs in the form of Marine Park management, National Park management, and work from the agricultural extension office. 
Fig. 10. Total annual emergy (energy memory) inflows. These values were calculated in Abel (2000); see the appendices of the work for detailed emergy analyses. Note especially the relatively high positions of tourism, construction, retail sales, and stevedoring. These are the major growth industries associated with development since the mid-1980s.

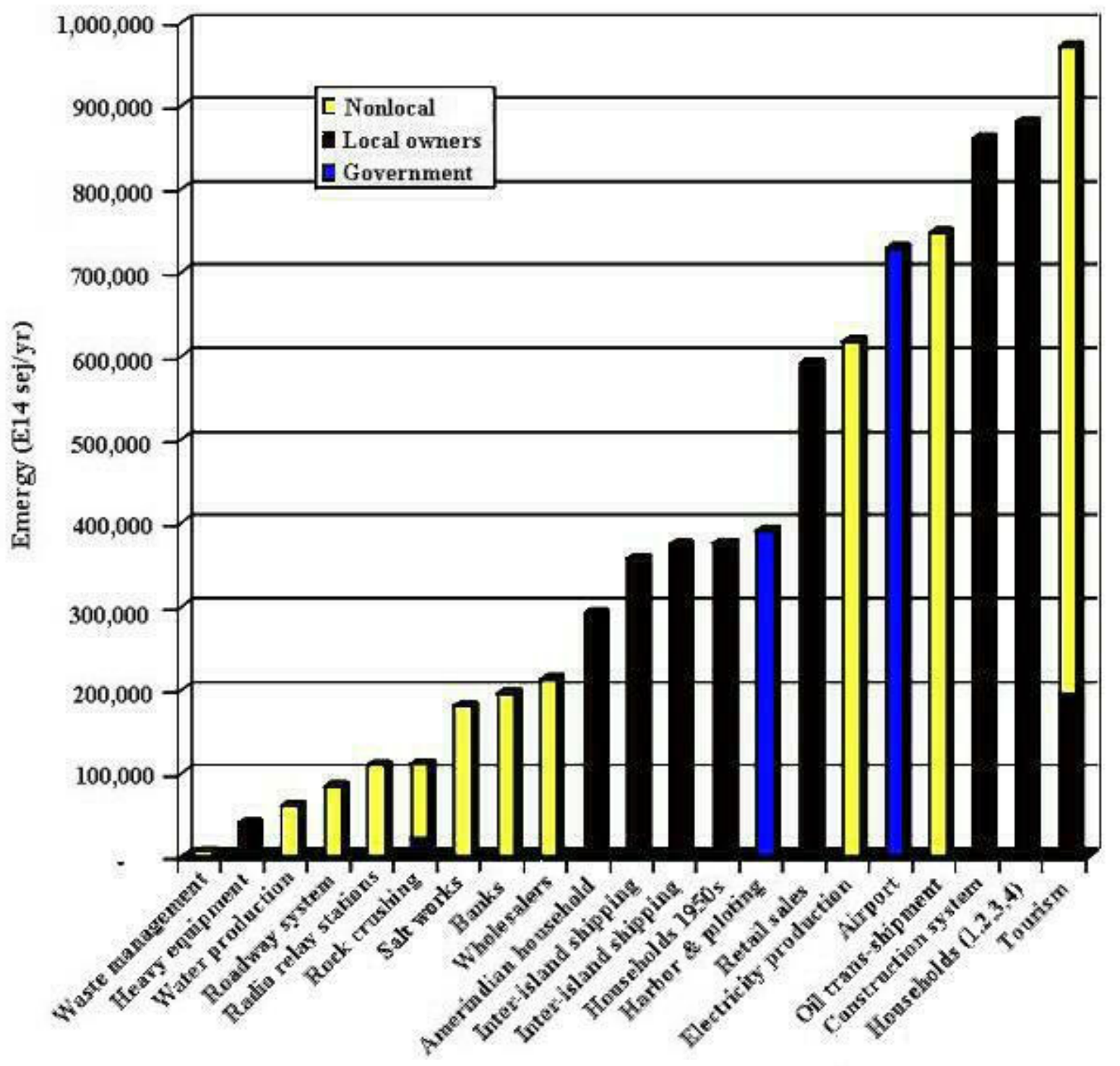

The implications of this graph sequence might be that Bonaire has reached a population size equivalent to its current development and should not further expand its population. In addition, it can be expected that more middle industries will appear with greater specialization.

\section{DISCUSSION}

Some general observations can be made about these findings. Unlike other nations that possess fossil fuels or mineral resources within their boundaries, Bonaire must import the great majority of its driving energy. Therefore, as shown in Fig. 14, it tends to grow from the top down. Energy enters the economy via transport industries that are controlled from abroad and via local monopolies, both government and private. In economies that possess such resources naturally, development may occur with a more uniform energy signature (Figure 2D). 
Fig. 11. Emergy (energy memory) inflows per establishment. The total emergy inflows from Fig. 10 were divided by the numbers of establishments to produce this bar graph.

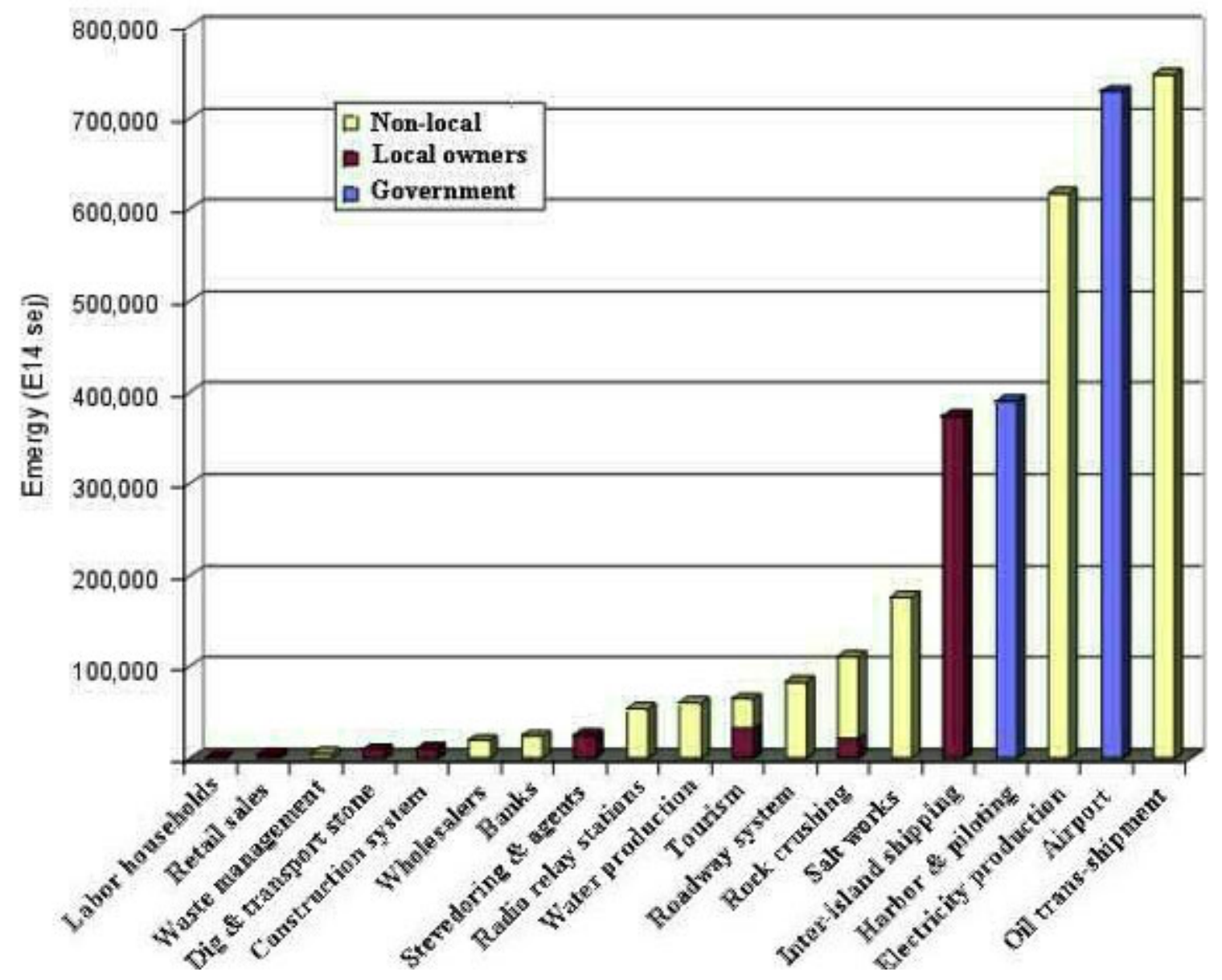

Fig. 12. Historic count of production subsystems.

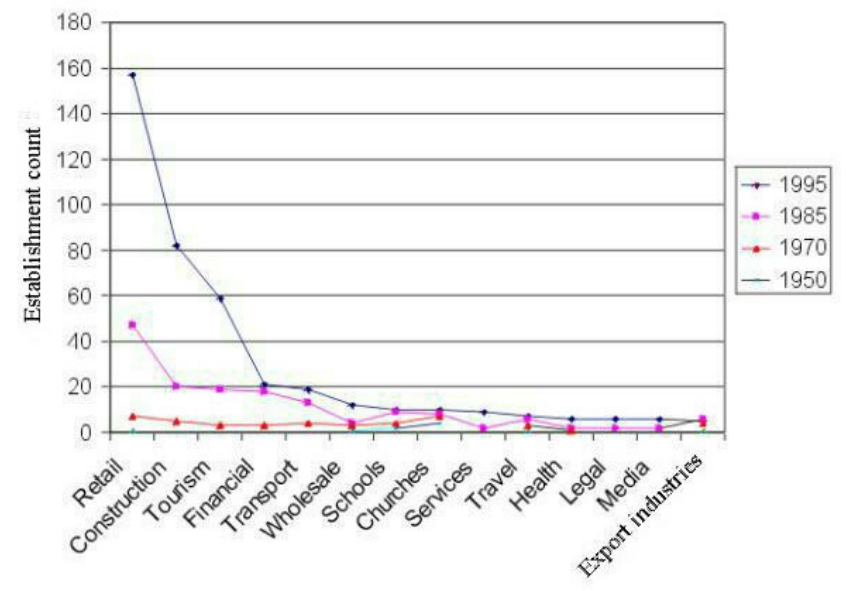

Alternatively, it may be that growth is always led by an uncoordinated and asymmetrical expansion as in Fig. 14. If that is the case, the years 1950 and 1995 in Fig. 14 might represent alternative periods of relative emergy stability, in which the island system was selforganized for maximum empower. Scientists who study complex systems have rejected the idea of a single ecosystem equilibrium or climax in favor of models of multiple stable states, often with pulsing or oscillating behavior between states (Fig. 15). This may indeed be what is observed for Bonaire.

One provocative implication of this research is in the area of human demography. It has often been assumed that population growth drives other processes in sociocultural evolution (Harris 1977, Johnson and Earle 1987). However, this diagram suggests that 
population density is a product of systemic relationships, organized by energy use and economic production; Stanish (2001) makes a similar observation. By this logic, development that enters a region from the top down, beginning with large export industries and a small population of elites, can be expected to lead to much larger populations of labor households and "many" smaller industries. Population growth in such economies is therefore not the "fault" of uncontrolled reproductive behavior, as is often proposed by policy makers in developed countries, but rather a result of the self-organization of the energy hierarchy in the context of export industries, i.e., a consequence and not a cause of the development sponsored by those same developed countries.

Fig. 13. Socioeconomic web, 1950-1995. In 1950, Bonaire's future changed as the result of a new constitution, which redefined its relationship with the Kingdom of the Netherlands. Dutch financial aid began to flow in and was invested in building infrastructure such as a port, an airport, and roads (Abel 2000). By the 1970s, several export industries had moved to Bonaire. Construction industries were emerging in support. A new water and electric plant was built. From 1950 to 1985 , Bonaire's population doubled, and much of the population was working for wages. Tourism was about to take off, encouraged from within and without.
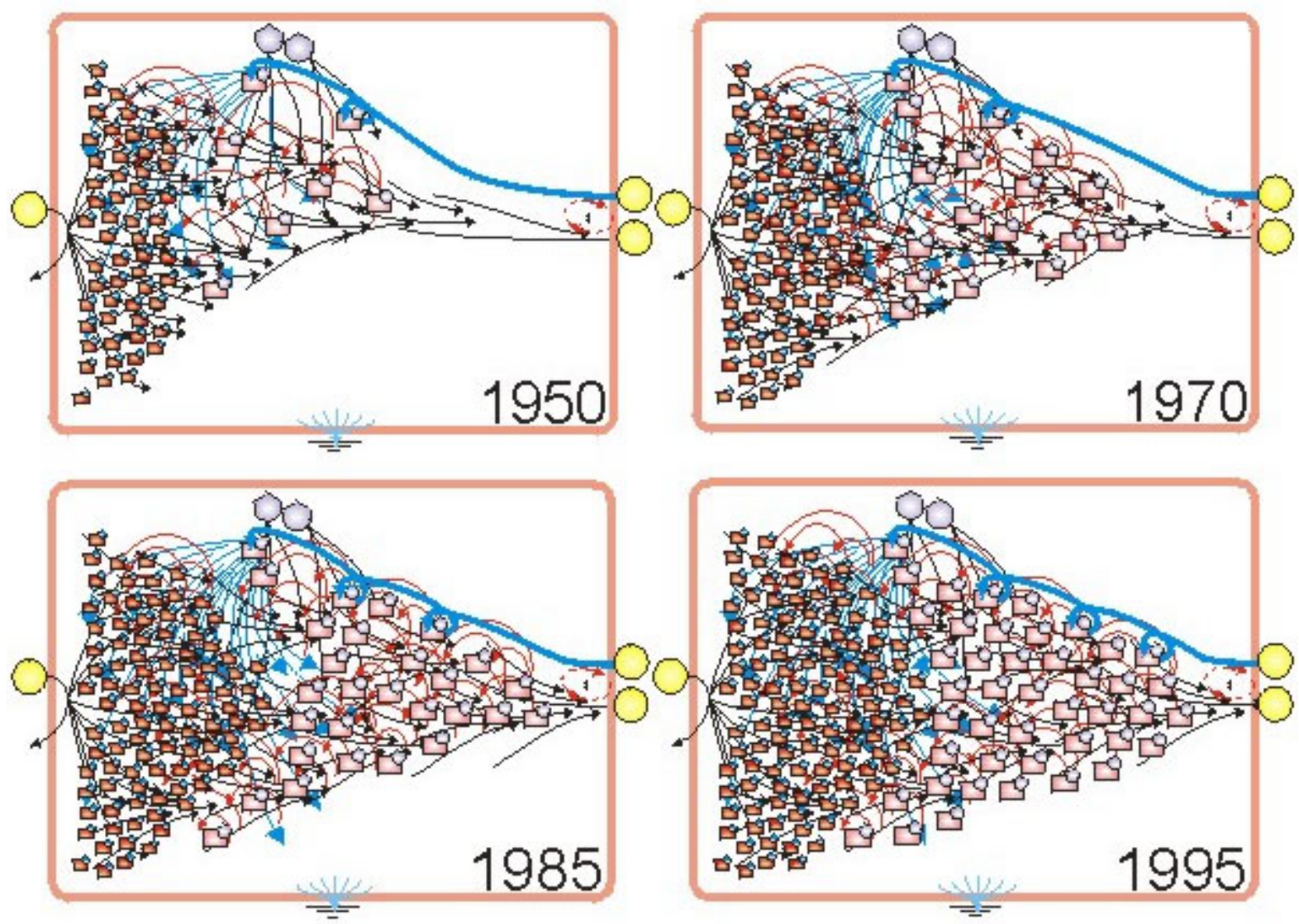

Science that limits itself to one scale in space or time has often suffered when larger- or smaller-scale events have undercut its conclusions. For years, many social scientists have endeavored to attain the precision of the micro-scaled experimentation found in other sciences. Some readers may be distressed by the absence in this paper of a detailed discussion of causeeffect relationships between particular social, economic, and ecological changes, with clearly defined links and feedback between variables. However, as noted by ecologists like Costanza et al. (1993), anthropologists like Keegan (1995), and originally by Holling (1964) and Levins (1966), scientific inquiry has different resolutions of realism, precision, and generality that depend largely on the focus and scale of analysis. Like other analyses of 
complex systems, this study of Bonaire achieves great generality and understanding by deliberately not following every link in a vastly complex causal web. Instead, the indications of self-organization are aggregate variables appropriate for the general question addressed here. This places this research within the integrative "second stream" of science described by Holling (1998), one that contrasts with conventional analytical, sometimes known as "reductionist," science and one that arguably is a better fit for many of the goals of anthropology and many other social sciences (Abel 1998).

Fig. 14. Production system hierarchies, 1950-1995. According to the definition of emergy (energy memory), the total emergies at each scale (in this case many, multiple, and single) are expected to be equivalent in a self-organized system that is maximizing empower, i.e., self-organizing for energy dissipation (Fig. 2E). If the three scales constructed for Bonaire are reasonable, it appears that the island system is again moving toward maximum empower or maximum flow of emergy. In complex-systems terms, these two points could be described as points on a surface with multiple stable states (Fig. 15). The four graphs coincide with the four systems diagrams in Fig. 13.

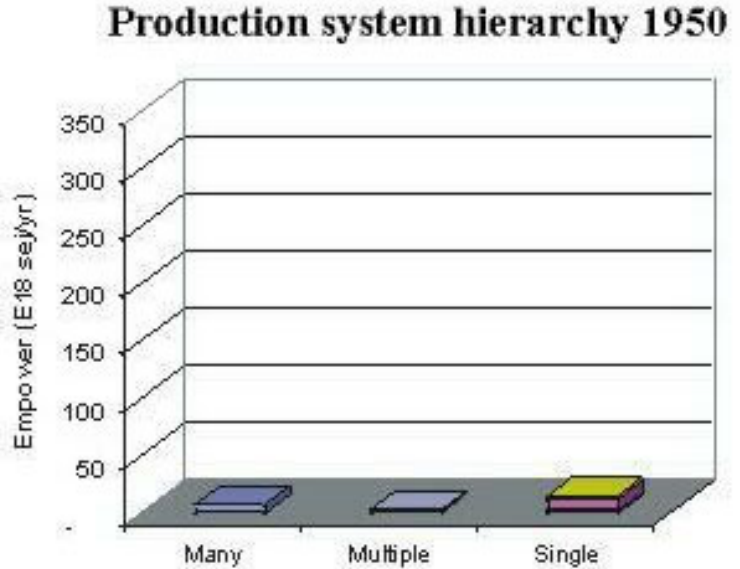

Production system hierarchy 1985

\section{Production system hierarchy 1970}

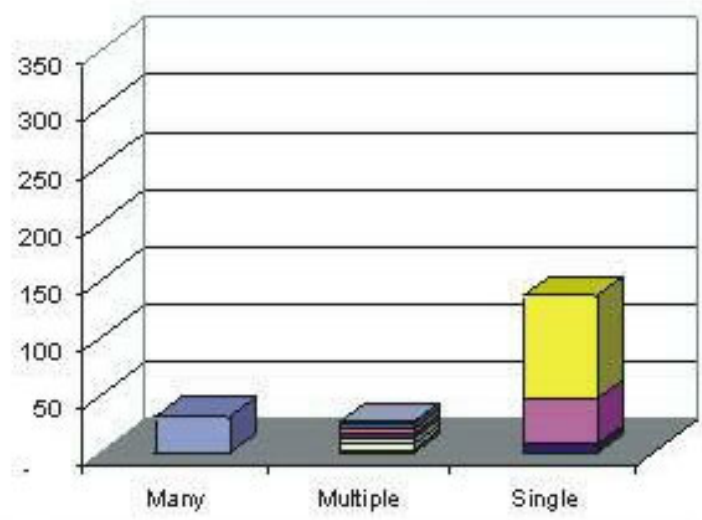

Production system hierarchy 1995

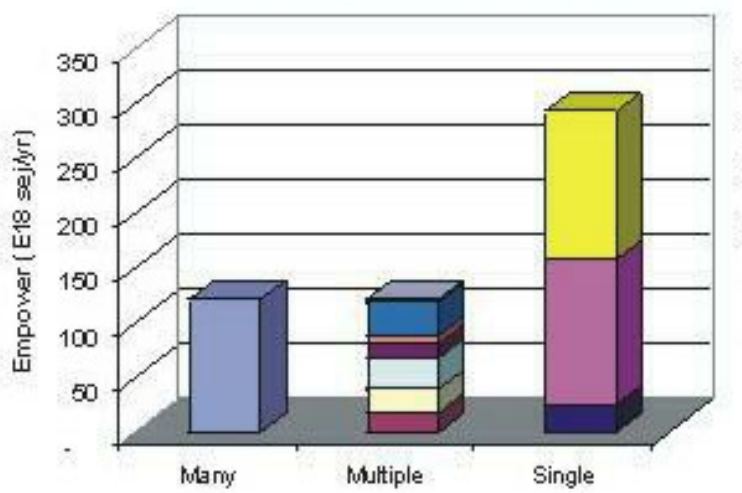

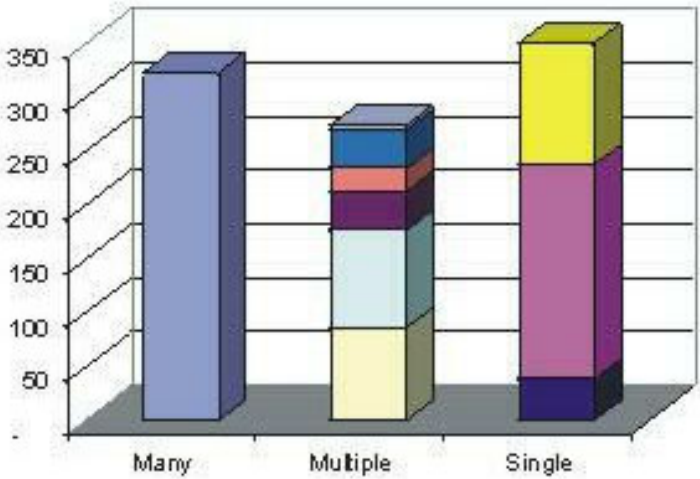

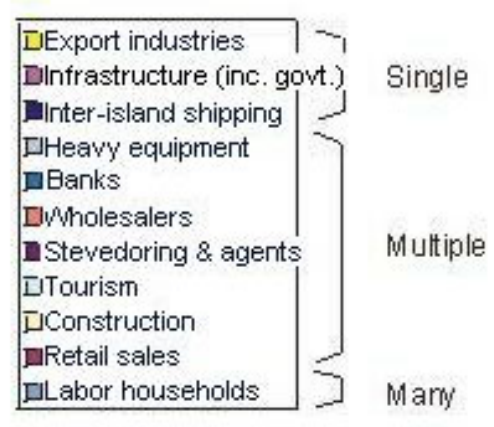


Fig. 15. Multiple stable states. A surface and ball have been used by complex-systems scientists to represent multiple stable states in systems. Disturbances to a system, such as the arrival of large export industries and government infrastructure to an island, can push the system out of one current stable state to another stable state.
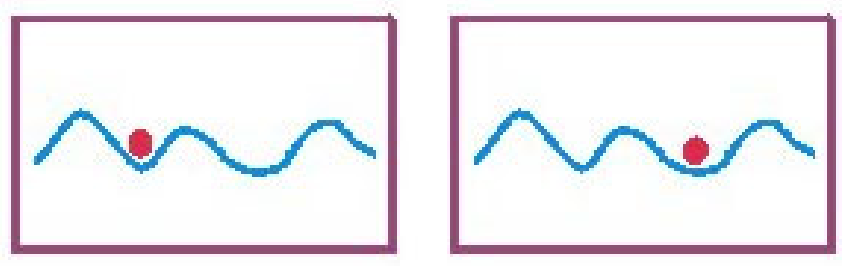

\section{CONCLUSIONS}

This paper argues that ecotourism development on Bonaire can be productively understood as a perturbation of a complex human-ecological system. New emergy flows associated with ecotourism have fueled transformations of the island ecology and sociocultural system. The resulting transformations of the social structure of Bonaire are both a consequence and a cause within the self-organizing process that has rippled through the island. Historical analysis has further placed this development event within the context of a whole-system transformation that was initiated in the 1950s by the influx of infrastructure and industry from public and private sources. Ecotourism can be understood to have "filled in" the middle of the production hierarchy of Bonaire as the sociocultural system moves toward a new, stable systems state. Population growth, interpreted from this perspective, has completed the transformation by expanding into production niches at smaller scales in the production hierarchy.

In closing, it is suggested that a desirable approach to understanding sociocultural dynamics could be one that incorporates at a theoretical level a model of the dynamics of complex systems. If complex systems are general systems that incorporate and transform matter, energy, and information, then complex-systems theory applied to sociocultural systems should give equal weight to understanding the dynamics of matter and energy in addition to the "informational" components most commonly emphasized by social theorists or managers. Furthermore, not only must emphasis be placed on the direct consumption of material resources by humans, but complex thermodynamic models of structure and function must be more broadly applied to the theory of human social structure and organizational dynamics observed at local, regional, and world systems scales.

Responses to this article can be read online at: http://www.consecol.org/vol7/iss3/art10/responses/index.html

\section{Acknowledgments:}

I would like to dedicate this manuscript to the memory of $H$. T. Odum, who passed away in September 2002. His life and work inspired his many students and those colleagues who were fortunate enough to work with him in Florida and elsewhere. We will miss him. The manuscript was improved by comments from $R$. Stepp and three anonymous reviewers.

\section{LITERATURE CITED}

Abel, T. 1998. Complex adaptive systems, evolutionism, and ecology within anthropology: interdisciplinary research for understanding cultural and ecological dynamics. Journal of Ecological Anthropology 2:6-29. Available online at http://guallart.dac.uga.edu/jea/abel.pdf.

Abel, T. 2000. Ecosystems, sociocultural systems, and ecological-economics for understanding development: the case of ecotourism on the Island of Bonaire, N.A. Dissertation, University of Florida, Gainesville, Florida. Available online at http://etd.fcla.edu/etd/uf/2000/ane0595/Abel.pdf.

Abel, T. 2002. Social structure and ecotourism development on Bonaire. Pages 210-221 in M. Brown, editor. Proceedings of the Second Biennial Energy Research Conference. Center for Environmental Policy, University of Florida, Gainesville, Florida.

Adams, R. N. 1982. The emergence of hierarchical social structure: the case of late Victorian England. Pages 116-131 in W. C. Schieve and P. M. Allen, editors. Self-organization and dissipative structures: applications in the physical and social sciences. University of Texas Press, Austin, Texas, USA.

Adams, R. N. 1988. The eighth day: social evolution as the self-organization of emergy. University of Texas Press, Austin, Texas, USA.

Bourdieu, P. 1986. The forms of capital. Pages 241-258 in J. G. Richardson, editor. Handbook of theory and research in the sociology of education. Greenwood, New York, New York, USA. 
Bourdieu, P. 1989. Social space and symbolic power. Sociological Theory 7(1):26-63.

Brown, M. T., and S. Ulgiati. 1999. Emergy evaluation of the biosphere and natural capital. Ambio 28:486-493.

Costanza, R., L. Wainger, C. Folke, and K.-G. Maler. 1993. Modeling complex ecological economic systems: toward an evolutionary, dynamic understanding of people and nature. BioScience 43:545-555.

Durkheim, E. 1893. The division of labor in society. Translation by G. Simpson. Free Press, Glencoe, Illinois, USA.

Ellen, R. 1982. Environment, subsistence and system: the ecology of small-scale social formations. Cambridge University Press, Cambridge, UK.

Giddens, A. 1984. The constitution of society: outline of the theory of structuration. Polity, Oxford, UK.

Hall, T. D., editor. 2000. A world-systems reader: new perspectives on gender, urbanism, cultures, indigenous peoples, and ecology. Rowman and Littlefield, Lanham, UK.

Harris, M. 1979. Cultural materialism: the struggle for a science of culture. Random House, New York, New York, USA.

Hawley, A. H. 1950. Human ecology: a theory of community structure. Ronald Press, New York, New York, USA.

Holland, D., and N. Quinn. 1987. Cultural models in language and thought. Cambridge University Press, Cambridge, UK.

Holling, C. S. 1964. The analysis of complex population processes. Canadian Entomology 96:335-347.

Holling, C. S. 1998. Two cultures of ecology. Conservation Ecology 2(4):4. [online] URL: http://www.consecol.org/vol2/iss2/art4/index.html</a.

Johnson, A. W., and T. Earle. 1987. The evolution of human societies: from foraging group to agrarian state. Stanford University Press, Stanford, California, USA.

Keegan, W. F. 1995. Modeling dispersal in the prehistoric West Indies. World Archaeology 26:400-420.

Labor Office. 1993. Labor totals by companies. Labor Office, Kralendijk, Bonaire.

Levins, R. 1966. The strategy of model building in population biology. American Scientist 54:421-431.

Marx, K. 1967. Capital: a critique of political economy. International Publishers, New York, New York, USA.

Odum, H. T. 1971. Environment, power and society.
Wiley, New York, New York, USA.

Odum, H. T. 1983. Systems ecology. Wiley, New York, New York, USA.

Odum, H. T. 1996. Environmental accounting: emergy and decision making. Wiley, New York, New York, USA.

Odum, H. T. 2000. Handbook of emergy evaluation: folio 2, emergy of global processes. Center for Environmental Policy, University of Florida, Gainesville, Florida.

Odum, H. T., and E. C. Odum. 1976. Energy basis for man and nature. McGraw-Hill, New York, New York, USA.

Odum, H. T., and E. C. Odum. 2000. Modeling for all scales: an introduction to system simulation. Academic Press, San Diego, California, USA.

Odum, H. T., and E. C. Odum. 2001. A prosperous way down: principles and policies. University Press of Colorado, Niwot, Colorado, USA.

Prigogine, I., and I. Stengers. 1984. Order out of chaos: man's new dialogue with nature. Bantam Books, Toronto, Ontario, Canada.

Sanderson, S. K. 1995. Civilizations and world systems: studying world historical change. AltaMira Press, Walnut Creek, California, USA.

Spencer, H. 1876. Principles of sociology. Volume 1. Appleton, New York, New York, USA.

Stanish, C. 2001. The origin of state societies in South America. Annual Review of Anthropology 30:41-64.

Turner, J. H. 1998. The structure of sociological theory. Sixth edition. Wadsworth, Belmont, California, USA.

Wallerstein, I. 1974. The modern world system I: capitalist agriculture and the origins of the European world economy in the sixteenth century. Academic Press, New York, New York, USA.

Weber, M. 1964. The theory of social and economic organization. Free Press, New York, New York, USA.

White, L. A. 1959. The evolution of culture: the development of civilization to the fall of Rome. McGrawHill, New York, New York, USA.

Wicken, J. S. 1987. Evolution, thermodynamics, and information: extending the Darwinian program. Oxford University Press, New York, New York, USA. 